RAD Conference Proceedings, vol. 5, pp. 1-8, 2021

ISSN 2466-4626 (online) | DOI: 10.21175/RadProc.2021.01

www.rad-proceedings.org

\title{
CANCER IN THE COUNTRIES OF THE SEE (BALKANS) REGION AND THE FUTURE PARTICLE THERAPY CENTER - SEEIIST
}

\author{
Mimoza Ristova ${ }^{1}$, Manjit Dosanjh², Herwig Schopper² \\ ${ }^{1}$ Physics Department, Faculty of Natural Sciences and Mathematics, University Ss Cyril and Methodius, Skopje, North \\ Macedonia \\ ${ }^{2}$ CERN, Geneva, Switzerland
}

\begin{abstract}
Purpose. A recent initiative was launched for establishing the South-East European International Institute for Sustainable Technologies (SEEIIST), a pan European research infrastructure (RI) which will provide a cutting-edge technology for (a) radiotherapy treatment with accelerated protons and ions and (b) multidisciplinary fundamental research involving accelerated ion beams. To justify the initiative for building the SEEIIST facility for cancer treatment, a study was conducted to estimate the time progress of the cancer incidence and mortality due to cancer in the countries of the SEE region. Methods and materials. The demography and the economic development of the SEE region were studied in relation to their emigration rate (brain drain). Time development of the incidence and mortality were studied for the SEE countries from the data available at Globocan of the IARC@WHO. Cancer epidemiology data were collected and studied by using the countries' cancer datasheets from the World Health Organization (WHO). The top ten cancers were presented for the SEE countries and for the region as a whole. Results. From the available data it is evident that the incidence and the mortality, both grow with time in the SEE region, unlike in the developed European countries chosen for reference, where the mortality declines with time. The occurrence of breaking points in curves mortality $v s$. time is evident for all the analyzed SEE countries. Many of these points coincide with changes in the societal aspects (security, politics and/or economy). Conclusion. The emerging research infrastructure SEEIIST will mitigate the brain drain from SEE, and contribute in overcoming the historical friction in the turbulent Balkan region, offering research opportunities in many fields related to accelerated ions, foster, research, innovation and knowledge transfer, facilitate radiational therapy with particles to the cancer patients of the SEE region, reducing the growing cancer mortality, thereby. SEEIIST will be developed as a strong commitment of the SEE countries' governments and common effort in science diplomacy of the international community. The central research facility will be based in one of the ten SEE countries. In parallel with developing the principal RI, several SEEIIST HUBs and NETWORKs will be developed for different SEE countries in support to the SEEIIST sustainability. To provide sustainability of the SEEIIST RI, a GREEN energy HUB (Green power plant for powering SEEIIST) will be set. Also, an IT HUB (providing big data analysis, machine learning and artificial intelligence for SEEIIST), Imaging HUB (developing novel imaging solutions for ion therapy for SEEIIST), etc. Furthermore, several combined SEE and western European networks will be established, such as the Training network, Radiobiology Network, Network of Oncologists, Network of Veterinary scientists, with their central coordination offices located in different SEE countries, with the objective to start joint research related primarily to the cancer treatment but also to other research disciplines.
\end{abstract}

Keywords: Cancer in SEE region, Balkans, Emigration, Brain Drain, Depopulation, Cancer epidemiology, Cancer Incidence, Cancer Mortality, Breaking Points, SEEIIST, Science and diplomacy

\section{INTRODUCTION}

Cancer is the second leading cause of death globally. The number of new cancer patients in the world is in constant growth. The number of new cancer cases in 2018 was 18.1 million, where as 9.6 million people died and 43.8 million people are living with cancer [1-2]. It has to be noted that approximately $70 \%$ of cancer deaths come from low- and middle-income countries [3]. The fight against cancer is among the top societal priorities. The battle with cancer is most challengeable in the development of new cancer therapy modalities for cases that are difficult to treat, such as cancers in the childhood, deep-seated and radioresistant cancers.
Demographic indicators of the increasing world population size, life expectancy and ageing populations (particularly in higher-income countries), along with the reduction of many other causes of deaths, implies that the total number of cancer deaths will continue to increase [3].

South-East European (SEE) countries are in the Balkan peninsula (Figure 1) being populated with about 43 million inhabitants: Albania ( $3 \mathrm{M})$, Bosnia and Herzegovina (3.8 M), Bulgaria (7.1 M), Croatia (4.3 M), Greece (10.7 M), Kosovo ${ }^{* 2}$ (1.9 M), Montenegro (o.6 M), North Macedonia (2.1 M), Serbia (7.1) and Slovenia $(2.1 \mathrm{M})$. Besides the geographical proximity, they share some common historical, political and societal challenges.

\footnotetext{
“mima.ristova@gmail.com, mristova@pmf.ukim.mk

${ }^{2}$ In this document, the designation to Kosovo is without prejudice to positions on status and is in line with UNSC 1244/1999 and the ICJ opinion on the Kosovo Declaration.
} 


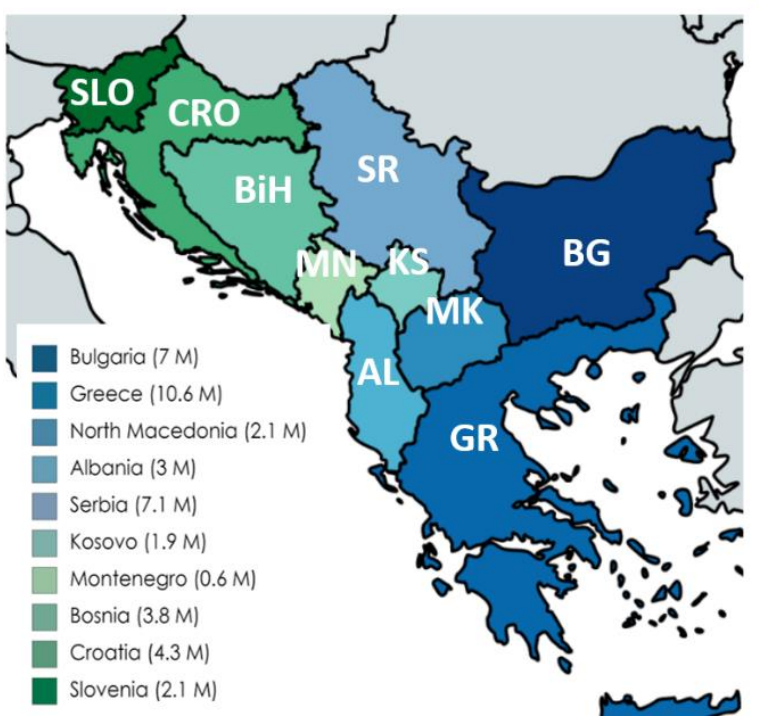

Figure 1. Geographical region of Balkans, also part of the SEE region.

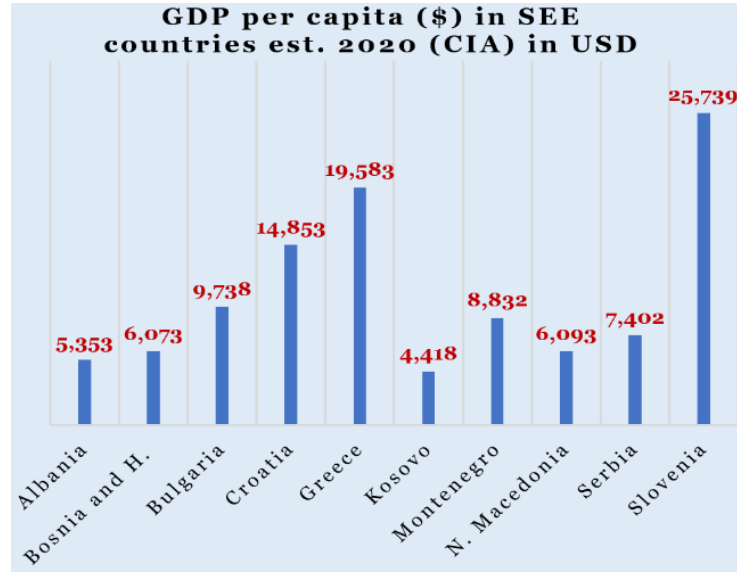

Figure 2. GDP/capita of the countries of the SEE region in 2020 (Source CIA Country factsheets).

Currently, there are SEE countries that are part of EU (Bulgaria, Croatia, Greece and Slovenia), while the other are Associated members. According to the publicly available data from the World Bank [4], seven out of ten SEE countries are middle-income countries with underdeveloped economies as their gross domestic products (GDP) per capita indicates (Figure 2). Figure 3 presents the time evolution of the GDP/capita of the SEE countries. As evident, seven out of 10 countries (currently the non-EU countries) show very slow economic progress.

Besides the challenges with the economic development, majority of the SEE countries also encounter problems with decreasing of their population [5], i.e., emigrations of the young, prosperous and highly skilled population. As the young talent leaves (brain-drain) their home countries, economic prospects decline even further. Figure 4 shows the emigration progress (depopulation of SEE) during the last 40 years (1980-2020).
GDP/capita in SEE region in USD

(1990-2020)

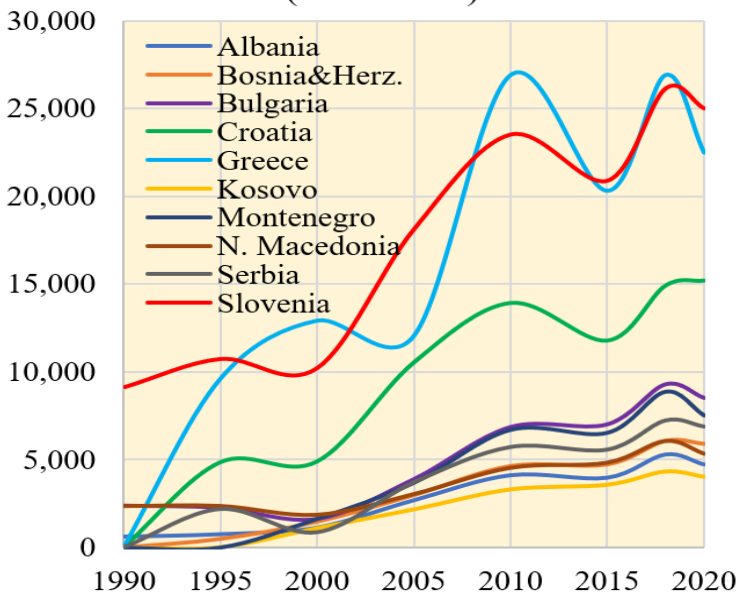

Figure 3. Time evolution of the GDP/capita in the SEE countries during the last 30 years (1990-2020).

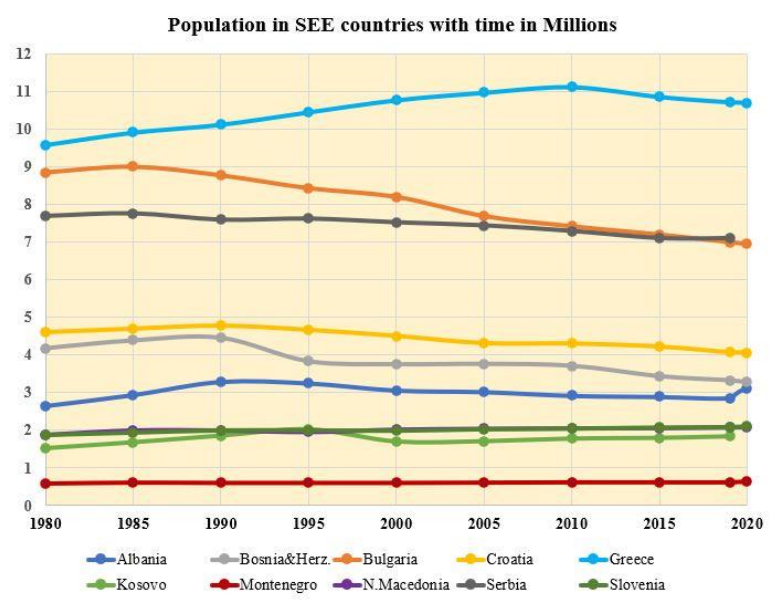

Figure 4. Trends of demography: population dynamics in SEE countries. Note: curves of North Macedonia and Slovenia overlap.

The reason of the brain-drain should be sought in the fact that most of the SEE region reveals insufficient capacity to create satisfactory conditions to retain talented people. The Global competitiveness index is an indicator of the ability of each country to retain talent. In other words, the ranking list made by the World Economic Forum shows the capability of the countries to create prosperous jobs for highly talented young people. The results of ranking 141 countries in 2019 [6] (partly listed in Table 1) shows that eight SEE countries are ranking between 59 and 92 due to the sky-high youth unemployment that drives the emigration from the SEE region (as was evident from Figure 4). This ranking indicates the intensity of the driving force that pushes the young and talented people to desert their SEE homelands, seeking professional development, valorization and recognition of their talent abroad. 
M. Ristova et al., Cancer in Balkans and SEEIIST-Hadron Therapy Center, RAD Conf. Proc., vol. 5, 2021, 1-8

Table 1. Global competitiveness Index ranking 2019

\begin{tabular}{|c|c|}
\hline Country & Rank in 2019 \\
\hline Singapore & 1 \\
\hline USA & 2 \\
\hline Hong Kong & 3 \\
\hline Netherlands & 4 \\
\hline Switzerland & 5 \\
\hline Slovenia & 35 \\
\hline Bulgaria & 49 \\
\hline Greece & 59 \\
\hline Croatia & 63 \\
\hline Serbia & 72 \\
\hline Montenegro & 73 \\
\hline Albania & 81 \\
\hline North Macedonia & 82 \\
\hline Bosnia and Herz. & 92 \\
\hline Congo & 139 \\
\hline Yemen & 140 \\
\hline Chad & 141 \\
\hline
\end{tabular}

Cancer Incidence 2018 [cases in $100,000]$

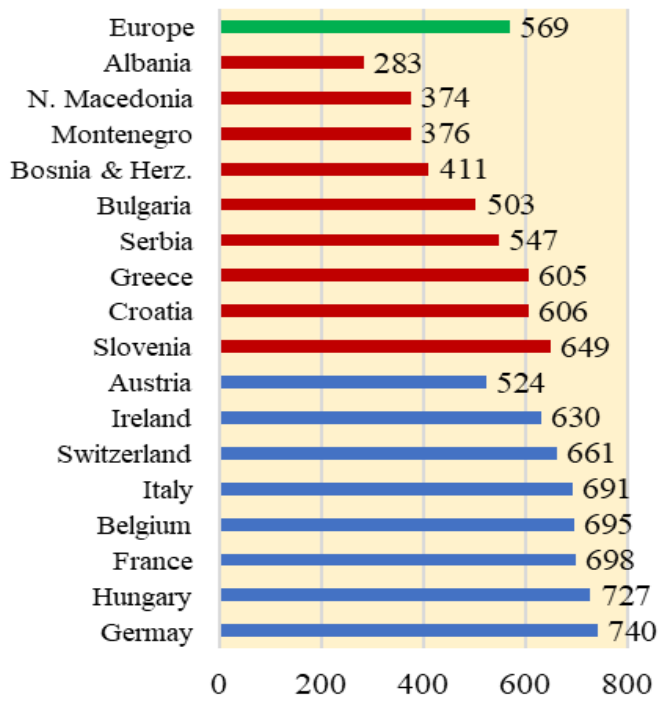

Figure 5. Cancer Incidence in 2018 in the SEE countries and some Western European countries for comparison.

Furthermore, the countries of the SEE region share common challenges in their health management systems, in particular, the cancer. Figure 5 presents the cancer incidence in 2018 (crude rate on 100,000 population) in the SEE countries, but also in some reference European countries for which data are available at the Global Cancer Observatory - Globocan [7], International Agency for Research on Cancer IARC [2] at World Health Organization (WHO). As evident from Figure 5, the incidence in the non-EU SEE countries is lower than that of average Europe, especially in the case of Albania, North Macedonia, Montenegro and Bosnia and Herzegovina. The lower incidence detected in the SEE countries could be partly attributed to the underdeveloped diagnostic capacities of these countries, lack of skilled personnel and lack in cancer screening programs.

Mortality-to-Incidence ratio (MIR) is a parameter that is calculated as a ratio between the number of patients who died due to cancer in a specific year
(Mortality) and the number of new patients that were diagnosed with cancer in the same year (Incidence). This parameter measures the countries' abilities to manage cancer.

Herein, Figure 6 shows the Mortality-to-incidence ratio for the SEE countries and some Western European countries for comparison. As could be seen from Figure 6 , the fatal outcome of cancer is higher than the average Europe's for 6 out of the presented 9 SEE countries, whereas Bosnia and Herzegovina showed the highest percentage of MIR ( $63 \%$ of the cancer patients with fatal outcome).

This sky-high fatality could be attributed to the weak economic power and thus the lower availability of diagnostics equipment, the radiation therapy and other cancer treatment modalities in their health systems.

SEE region also diverges from the rest of the Western and Central European region because it lacks a facility for treating cancer with protons and heavier ions. Such kind of centres that facilitate a proton or Cions radiation therapy is growing in Europe [1] and worldwide [8].

\section{Mortality-to-Incidence 2018 [\%]}

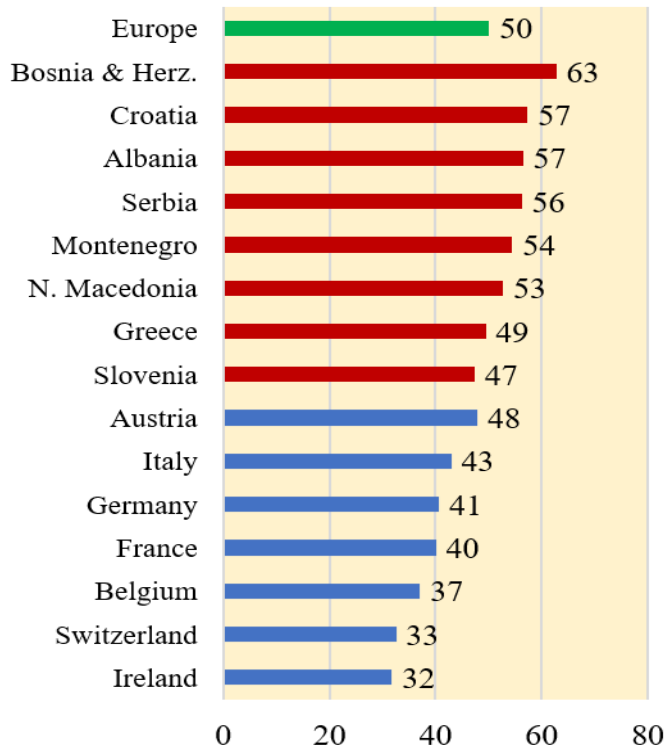

Figure 6. Mortality-to-Incidence (MIR) ratio in 2018 for the SEE countries and some Western European countries for comparison.

South-East European International Institute for Sustainable Technologies - SEEIIST [9] is a Synchrotron Accelerator-based Research Infrastructure for Cancer Therapy and Biomedical and multidisciplinary research with ion beams which will provide HT to the citizens of the SEE countries who currently have no such facility [10-12]. The ion beam day-time of SEEIIST will be evenly shared between the specialists who deliver ion-therapy to 400 patients at the beginning, progressing to 1000 patients when fully optimized [13], and to the fundamental scientists from multiple disciplines (radiobiology, veterinary science, material science, radio-isotopes for medicine, etc.). SEEIIST is aiming to transfer the positive effects of 
science and diplomacy, to mitigate the historical friction that still persists among the SEE countries, following the positive experience of the European research infrastructure (RI), CERN in Switzerland and France, and the joint synchrotron RI SESAME [14], designed for seven countries in the Middle East (including Israel and the Palestinian authority). SEEIIST facility is currently in the second phase of technology development. Also, it is at the stage for defining the criteria for site selection within the SEE region and formation of dispersed HUBs and Networks. SEEIIST is expected to be fully commissioned in 2029-2030 [11]. Developing the SEEIIST RI implies that the SEE region should act as a compact and integrated community with joint management, addressing the common challenges, such as the brain-drain, economic development, research and innovation uplift and learn how to peacefully work together in the joint resources to combat cancer.

\section{MAterials AND MEthods}

Herein, we present the results of our analysis of the progression with time of the number of cancer patients in the SEE region, including cancer incidence, and mortality crude rates (cases in 100,000 population). The data were provided from the open source Globocan@WHO. This research could be very useful for SEE countries' cancer treatment stakeholders in their timely strategic planning and budgeting for the diagnostics and treatment equipment for the benefits of future cancer patients. This research intends to trigger a "wake-up call" that could bring the SEE region together in creation/recreation of an alliance against their common enemies - cancer, brain-drain, poverty, etc. The ultimate intention of this cancer statistics research is to increase the awareness of the influential visionaries in SEE healthcare stakeholders, to jointly facilitate the coming SEEIIST - ion therapy treatment facility become a reality [11] which will bring improvements in the SEE healthcare systems, mitigating the brain-drain in the SEE region.

\section{RESULTS AND DISCUSSION}

\subsection{Cancer epidemiology in 2019 in the SEE region}

Below, we present the cancer epidemiology in the SEE region (Table 2). The numbers on the most right show the sum of the estimated age-standardized (World) incidence rates in 2018 of the 10 cancers with the highest incidence in the SEE region. The figures from Kosovo were unfortunately unavailable. Table 2 gives a clear view of the SEE regional cancer epidemiology. It is evident that the top 5 cancer sites are lung, colorectum, breast, prostate and bladder, comprising over $50 \%$ of the overall cancer incidence in 2018.

For comparison, the Global cancer epidemiology in 2012 showed that the incidence of the top 5 cancers is as follows: breast, lung, prostate, head and neck, and colorectum [15-16]. From these projections, it appeared that approximately $14 \%$ of all cancer patients are lung cancers, making it the "number one" cancer in the SEE region as a whole, although on the national lists of Croatia and Montenegro, it appears as \#2 in and in Bulgaria and Slovenia it is ranked \# 3 .
Table 2. Top 10 cancers 2018 requiring radiotherapy in SEE region (except Kosovo). The ranking was made by absolute numbers of incidence in each of the SEE countries by incidence (left) and top 10 in SEE region as a whole (right). The table on the right should be used as a legend for the table on the left. It appears that lung, breast and colorectal cancers are the most common in the region, as for Europe as a whole.
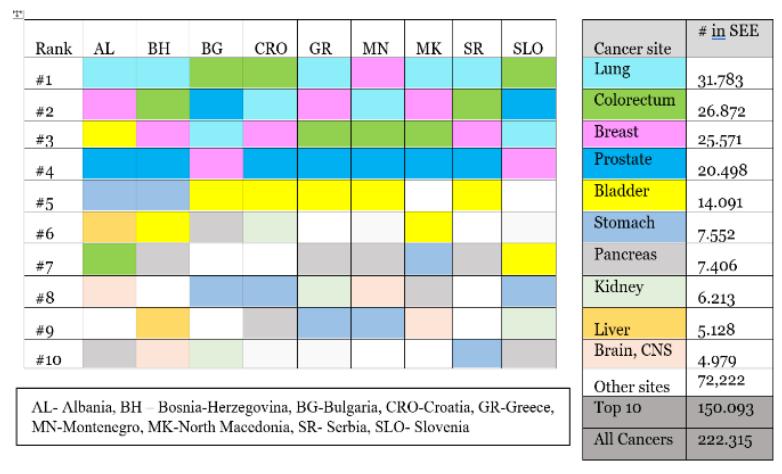

\subsection{Cancer Incidence in the SEE region}

Subject to this study were Cancer Incidence data that were registered during a longer history of recording, and with good quality and full country coverage. Such data were provided only for three SEE countries, Bulgaria, Croatia and Slovenia. Figure 8 shows a linear growth in the cancer incidence in three aforementioned SEE countries. The selected comparative countries (Island, Norway and Switzerland (Geneva canton only)) have a comparative population size with some SEE countries. It is also evident that similar linear course in the incidence growth with time elapse revealed the two European countries, Iceland and Norway. It is evident that for these countries the incidence growth goes slower in comparison to the SEE countries. In addition, one could see that the incidences for Slovenia and Croatia grow together with highest increment, following the same course, while as Bulgaria's incidence curve is inclined a bit lower. The lowest growth in the incidence is recorded for the Geneva Canton (the longest registry dataset from Switzerland). It is evident that the incidence rate substantially slows down (or even saturates) for Geneva Canton, revealing a breaking point at the year 2000.

The incidence with time curve of Geneva Canton shows saturation that could be explained with the abundance of diagnostics equipment, skilled diagnostics personnel and screening programs for early cancer detection, known to be available in Switzerland [17]. Hence, the greatest part of the incident cancer is detected with the currently available technology, implying that the small growth in the last decade is inflicted by the prolonged life expectancy and thus to the increased probability for cancer occurrence among the aging population. Previous analyses on the incidence have proven its correlation with the availability of diagnostics tools, making a clear difference between the "incidence" and the "detected cancers". The constantly fast-growing trend of the incidence of the presented SEE countries could be explained with the slower implementation of the new technologies due to their economic circumstances. Thus is the lower number of available diagnostics equipment per 100,000 population. 


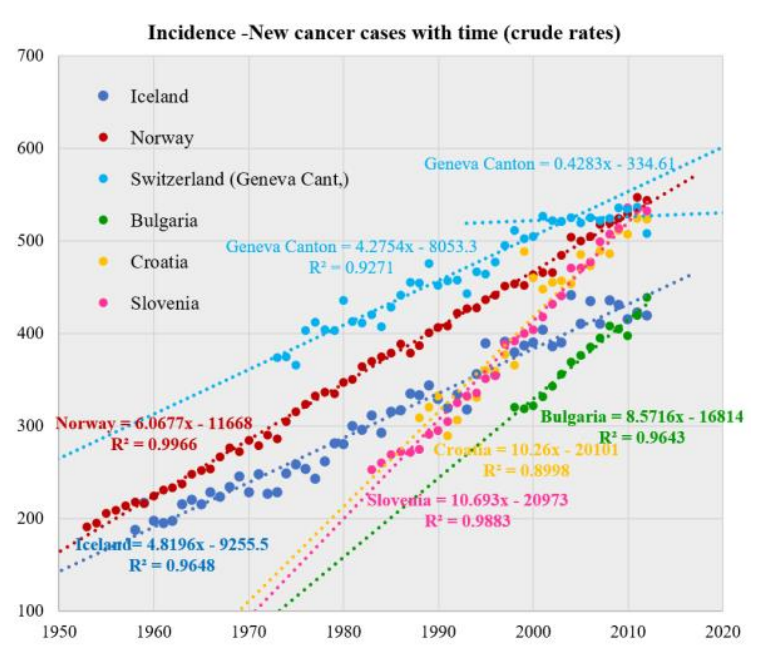

Figure 7. Time progression of the cancer incidence (number of patients that were diagnosed with cancer) for three SEE countries, Bulgaria, Croatia and Slovenia, and three European countries with relatively long existing cancer registries, Iceland, Norway and Geneva Canton (Switzerland).

\subsection{Mortality due to cancer in SEE region}

As was mentioned before, the cancer incidence depends on the diagnostics equipment availability. However, the mortality is correlated to the availability of cancer treatment equipment and up-to-date treatment modalities The time progression of the mortality due to cancer (crude rate, per 100,000 population, all cancers, all ages, both sexes) in some European countries that provide reliable data and were not involved in any political turmoil during the post IIWW history. As obvious from Figure 8, Island shows a slow perpetual growth in the mortality due to cancer with the years. However, one can see that the mortality curve of Norway and Switzerland (represented through the Geneva Canton registry records) shows a different behavior. Herein one can observe breakpoints that change the course of the mortality curves from inclination to declination that occur around 1990-1995.

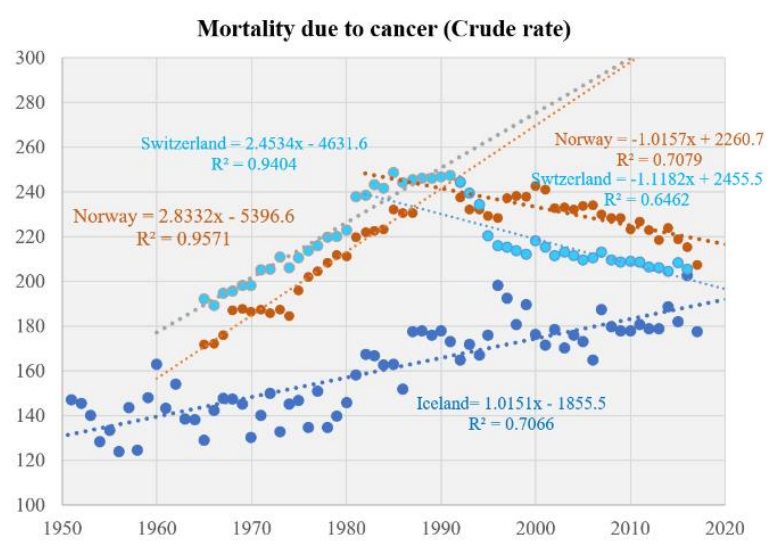

Figure 8. Time progression of the Mortality due to cancer in several European countries (Norway, Switzerland, Iceland). Breakpoint is observed around 1990-1995 for Switzerland and Norway.
These positive abrupt changes (slowing down) in the mortality rate from increase into decrease could be related to the implementation of the cutting-edge technologies in their health systems of these two high income European countries, such as the Positron Emission Tomography, that became commercially available in 1990, and the Intensity Modulated Radiation Therapy (IMRT) that became commercially available in 1994. Nonetheless, such a change in the course of the mortality curve is not observed for Island (also a high-income European country in the same period), which is probably because of this countries' different cancer strategic planning.

Cancer Mortality - Bulgaria 1964-2020 (Crude Rate)

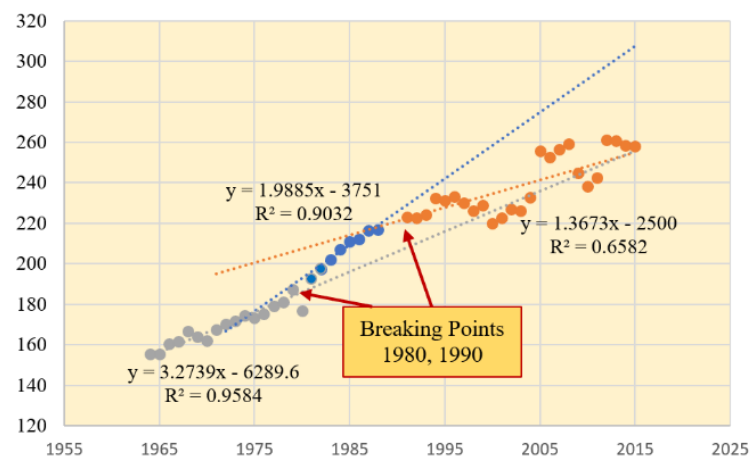

Cancer Mortality - Greece 1961-2020 (Crude Rate)

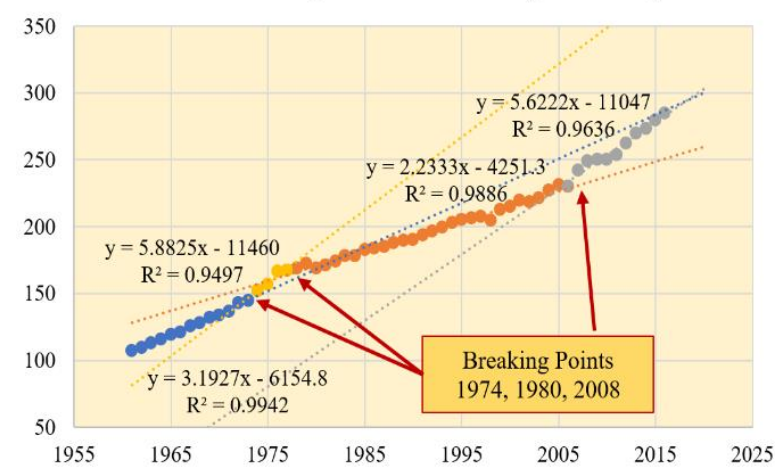

Cancer Mortality - Croatia 1987-2020 (Crude Rate)

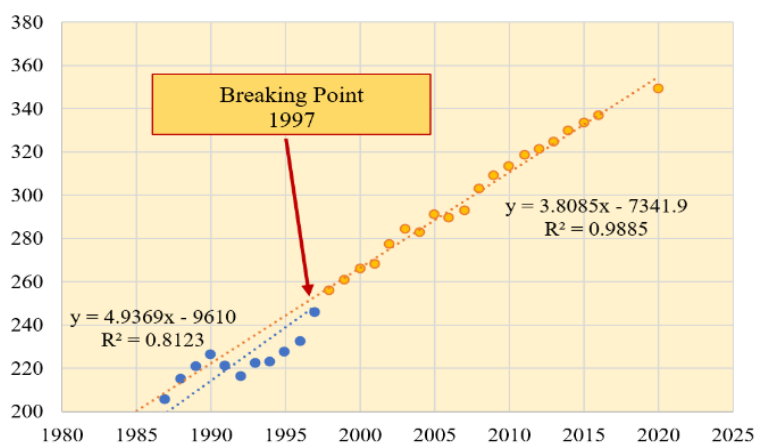



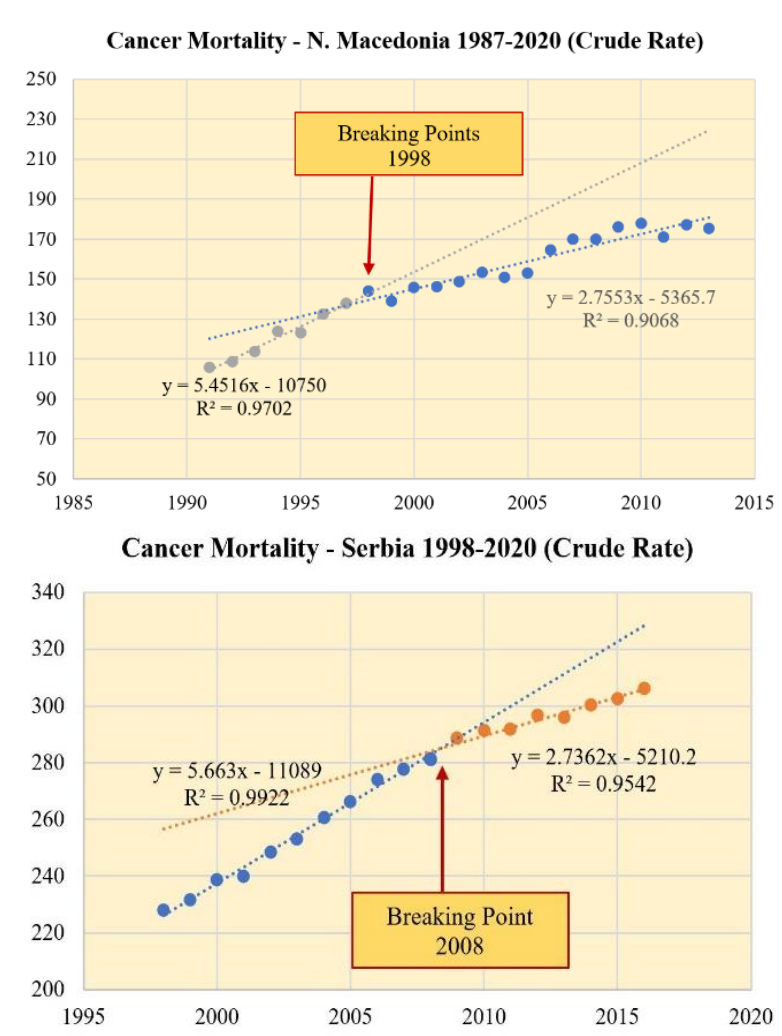

Cancer Mortality - Slovenia 1985-2020 (Crude Rate)

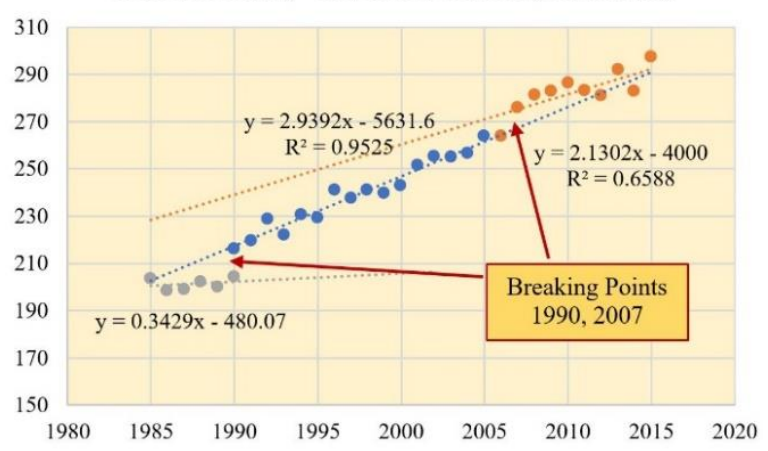

Figures 9. Time evolution of the mortality due to cancer (crude rate in 100,000 population) for the following SEE countries: Bulgaria, Croatia, Greece, North Macedonia, Serbia and Slovenia. Note: The accessible data from Albania and Montenegro were lower quality, and the data from Bosnia and Herzegovina, and Kosovo were unavailable.

The time evolution of the mortality due to cancer (crude rate in 100,000 population) in six SEE countries, Bulgaria, Croatia, Greece, North Macedonia, Serbia and Slovenia, is presented in Figure 9. As evident from the presented figures, the mortality curves vs. time show at least one breaking point. Some of the points indicate slowing down growing rate of the mortality but some indicate increase in the mortality in the given period of time. For instance, the mortality curves of North Macedonia and Serbia reveal one breaking point within the period 1997-2014. The other curves show more complex behavior, displaying two or more breaking points in the recorded periods. Herein, in the cases of Bulgaria and Greece, the course of the curve is much more complex and breaks multiple times, revealing an increased mortality rate and then a decreased mortality rate, or vice versa. One may compare the years at which these breaking points occur for the respective countries to some known historical events that introduced political and societal turmoil, typical for the unrest Balkan's area.

From Figures 9 it is evident that there are some historical events that inflicted either negative changes in the cancer incidence (such as wars, political or economic crisis) or positive proceedings that induced positive changes in the cancer mortality behavior (membership in the European Union). Those intensive circumstances are expected to affect the SEE countries' national economies and thus their cancer fighting strategies, either in a positive or negative way.

In Table 3, we present the detected braking points occurring for the six SEE countries from Figure 9, along with the years of the "shaky" events that induced drastic political, economic and/or security changes that affect the SEE countries' systems. For instance, the breaking points in the mortality curve of Greece $(1974,1980$ and 2008) closely coincide with the following events: $1974-$ Cyprus crisis (War with Turkey) at which point the mortality rate increased, 1981- Greece joining EU, a positive change after which the mortality rate slowed down, and finally, 2009 Government debt crisis recession, after which point the mortality rate increased again with the highest step ever. In the case of Serbia, the recorded data are outside the range after the Yugoslav war. The only evident change of the course of the cancer mortality occurs in the breaking point in 2008, which coincides with separation of Kosovo (independent territory). This "positive" change in mortality is normal since the nearly two million Kosovars were no more seeking health services (including RT cancer treatments) from Belgrade, but from elsewhere, improving the availability of the cancer treatment RT equipment for the rest of the Serbian population. Furthermore, one of the observed breaking points of positive change in the cancer mortality in Bulgaria in 1990 could be closely interpreted with the fall of the Eastern Block in 1989 and subsequent reorganization of the health systems with EU support.

Table 3. Breaking points in mortality curves in $6 \mathrm{SEE}$ countries, years of critical events/changes in security (wars), political crisis \& economic turmoil that affected Balkans.

\begin{tabular}{|c|c|c|c|}
\hline Country & $\begin{array}{l}\text { Breaking points } \\
\text { in mortality due } \\
\text { to cancer }\end{array}$ & Crisis/Change $1 / 2$ & Crisis/Change $2 / 3$ \\
\hline Bulgaria & $\begin{array}{l}1980 \\
1990\end{array}$ & $\begin{array}{l}1989 \\
\text { Fall of Eastern } \\
\text { block }\end{array}$ & $\begin{array}{l}2007 \\
\text { Joining EU }\end{array}$ \\
\hline Croatia & 1997 & $\begin{array}{l}1991 \\
\text { Yugoslav war }\end{array}$ & $\begin{array}{l}2013 \\
\text { Joining EU }\end{array}$ \\
\hline Greece & $\begin{array}{l}1974 \\
1980 \\
2008\end{array}$ & $\begin{array}{l}1974 \\
\text { Cyprus crisis (War } \\
\text { with Turkey) } \\
1981 \\
\text { Greece joining EU }\end{array}$ & $\begin{array}{l}2009 \\
\text { Government debt } \\
\text { crisis - recession }\end{array}$ \\
\hline $\begin{array}{l}\text { N. } \\
\text { Macedonia }\end{array}$ & 1998 & $\begin{array}{l}1991 \\
\text { Separation from } \\
\text { Yugoslavia (no war) }\end{array}$ & $\begin{array}{l}2001 \\
\text { War conflict }\end{array}$ \\
\hline Serbia & 2008 & $\begin{array}{l}1991 \\
\text { Yugoslav war }\end{array}$ & $\begin{array}{l}2008 \\
\text { Separation of } \\
\text { Kosovo from Serbia }\end{array}$ \\
\hline Slovenia & $\begin{array}{l}1990 \\
2007\end{array}$ & $\begin{array}{l}1991 \\
\text { Yugoslav war }\end{array}$ & $\begin{array}{l}2004 \\
\text { Joining EU }\end{array}$ \\
\hline
\end{tabular}




\section{CONCLUSION}

SEE countries share numerous common challenges, historical, economic, political and societal, and a limited access to RT of their patients to which should be addressed by expansion of their RT capacities, since it is a Global challenge. Having in mind that, from one side, the cancer incidence in the observed SEE countries is following a linear growth, the stakeholders can plan the adequate growth in the national radiotherapy services (19). On the other side, there are single and multiple breaking points in the mortality curves, which are not characteristic for the western European countries. Herein, one may suggest on a correlation between the growth in the mortality and perpetual political turmoil in the Balkans. The declination in the mortality rate due to positive historical changes and increase of the cancer mortality rate upon societal or economic turmoil is charting the typical cancer mortality for SEE (any respective country). In order to reach the stabile and sustainable socio-political state, such, as is indicative for the cancer mortality curves of Switzerland and Norway, the SEE countries need to boost a transformation towards long-lasting political partnership and joint economic development.

The latter could be achieved with the commitment to build up the emerging research infrastructure SEEIIST, according to the positive experience with CERN and SESAME, that will primarily mitigate the brain drain from SEE and contribute in overcoming the historical friction in the turbulent Balkan region. SEEIIST will offer cutting-edge research opportunities for young talented researchers in many fields related to accelerated ions, foster, research, innovation and knowledge transfer, facilitate radiational therapy with particles to the cancer patients of the SEE region, reducing the growing cancer mortality, thereby.

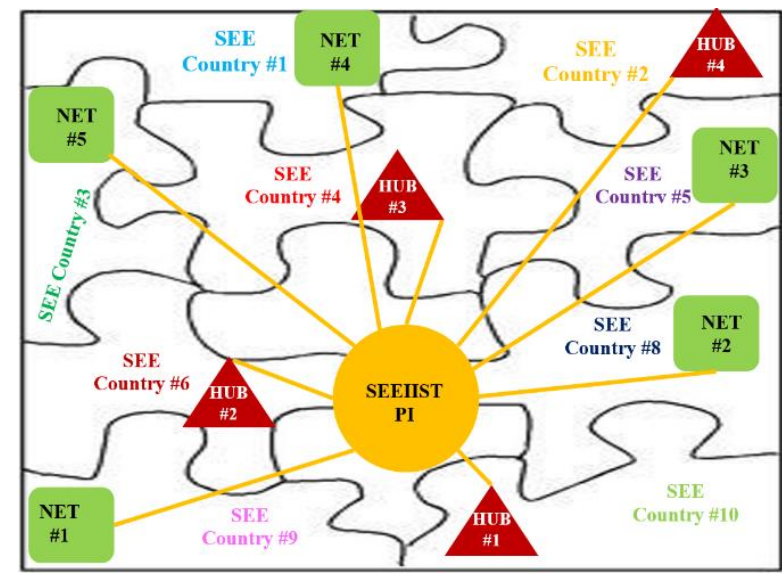

Figure 10. Fictitious map of the SEE region: SEEIIST principal research infrastructure (RI) located in one country, while as the dispersed HUBS and the coordination offices of the NETWORKS will be located in different SEE countries.

SEEIIST will grow as a strong commitment of the SEE countries' governments and common effort in science diplomacy of the international community. Besides the central research facility that will be located in one of the ten SEE countries, several SEEIIST HUBs and NETWORKs will be developed in parallel to perform support activities for the principal RI. All these
HUBs and NETWORKS will be located in different SEE country, to provide project sustainability and even involvement of all the mentioned SEEIIST countries, as charted in Figure 10 (Fictitious map of the SEE region with a principal RI SEEIIST and 4 HUBS and 5 NETWORKS). One of the dispersed HUBs will be devoted to the green energy, to generate green power to supply the principle SEEIIST infrastructure. IT HUB is essential for big data analysis, machine learning and artificial intelligence. Furthermore, imaging HUB will pursue research and develop novel imaging solutions for ion therapy. Moreover, several SEEIIST Networks will be established, joining together SEE and western European scientists, such as the Training network, Radiobiology Network, Network of Oncologists, Network of Veterinary scientists with their central offices in different SEE countries, to initiate the research related primarily to the cancer treatment but also to other research disciplines.

Acknowledgements: This research was supported by EU DG-RTD via a special instrument 'Service Facility in Support of the Strategic Development of International Cooperation in Research and Innovation $N^{\circ} 30-C E-0838742 / O O-87$.

\section{REFERENCES}

1. Radiotherapy In Cancer Care: Facing the Global Challenge, E. Rosenblatt, E. Zubizarreta, Eds., Vienna, Austria: IAEA, 2017.

Retrieved from:

https://www-

pub.iaea.org/MTCD/Publications/PDF/P1638 web .pdf

Retrieved on: November 1, 2020.

2. Latest global cancer data: Cancer burden rises to 18.1 million new cases and 9.6 million cancer deaths in 2018, Press release no. 263, IARC, Lyon CEDEX, France, 2018.

Retrieved from

https://www.iarc.fr/wpcontent/uploads/2018/09/pr263 E.pdf

Retrieved on: November 1, 2020.

3. M. Steverson, "Ageing and health", WHO, Oct. 4 , 2021.

Retrieved from:

https://www.who.int/news-room/factsheets/detail/ageing-and-health

Retrieved on: October 5, 2021.

4. U. Serajuddin, N. Hamadeh, "New World Bank country classifications by income level: 2020-2021", World Bank Blog, Jul. 1, 2020. Retrieved from:

https://blogs.worldbank.org/opendata/new-worldbank-country-classifications-income-level-2020$\underline{2021}$

Retrieved on: October 1, 2020.

5. EUROSTAT.

Retrieved from:

https://ec.europa.eu/eurostat/databrowser/view/ HLTH RS EQUIP custom 569701/bookmark/t able?lang=en\&bookmarkId =893a61 db-eacb-4633beff-996e7doa653d

Retrieved on: March 15, 2021.

6. World Economic Forum

Retrieved from:

http://www3.weforum.org/docs/WEF TheGlobalC ompetitivenessReport 2019.pdf

Retrieved on: January 12, 2021. 
7. GLOBOCAN

Retrieved from: https://gco.iarc.fr

Retrieved on: March 15, 2021.

8. ENLIGHT.

Retrieved from: https://enlight.web.cern.ch/

Retrieved on: March 15, 2021.

9. SEEIIST

Retrieved from: https://seeiist.eu/

Retrieved on: March 15, 2021.

10. CERN Yellow Reports: Monographs -A Facility for Tumour Therapy and Biomedical Research in South-Eastern Europe, U. Amaldi, ed., vol. 2, CERN2019-002, Geneva, Switzerland: CERN, 2019. https://doi.org/10.23731/CYRM-2019-002

11. U. Amaldi et al. "South East European International Institute for Sustainable Technologies (SEEIIST)", Frontiers in Physics, vol. 8, article no. 567466, pp. 601-611, Jan. 2021. https://doi.org/10.3389/fphy.2020.567466

12. R. N. Izairi Bexheti, M. M. Ristova, M. Dosanjh, "State-of-the-art and the future of particle therapy (perspectives for SEE countries)", Physics AUC vol. 30 (part II), pp. 246-262, 2020. http://ciso1.central.ucv.ro/pauc/vol/2020 30 par t2/pauc 2020 part2.html

13. M. Ristova, V. Gersan, U. Amaldi, H. Schopper M. Dosanjh, "Patients with cancer in the countries of South-East Europe (the Balkans) region and prospective of the Particle Therapy Center: SouthEast European International Institute for
Sustainable Technologies (SEEIIST)", Advances in Radiation Oncology, vol. 6, no. 6, article no. 100772, Aug. 2021.

https://doi.org/10.1016/j.adro.2021.100772

14. R. Baskar, K.A. Lee, R. Yeo, K-W. Yeoh, "Cancer and radiation therapy: Current advances and future directions", Int. J. Med. Sci., vol. 9, no. 3, pp. 193-199, 2012. https://doi.org/10.7150/ijms.3635

15. J.M. Borras et al., "How many new cancer patients in Europe will require radiotherapy by 2025 ? An ESTRO-HERO analysis", Radiotherapy and Oncology, vol. 119, no. 1, pp. 5-11, Feb. 2016. https://doi.org/10.1016/j.radonc.2016.02.016

16. M. M. Ristova et al., "Cancer patients, diagnostics and radiation therapy equipment in the countries of the SEE region", (submitted for publication), Journal of Global Oncology, 2021.

17. Planning national radiotherapy services: A practical tool, IAEA Human Health Series no. 14, Vienna, Austria: IAEA, 2010. Retrieved from:

https://www.iaea.org/publications/8419/planningnational-radiotherapy-services-a-practical-tool Retrieved on: November 1, 2020.

18. CERN.

Retrieved from: https://cern.ch/ Retrieved on: March 15, 2021. 